MUZIKOLOŠKI ZBORNIK - MUSICOLOGICAL ANNUAL VII, LJUBLJANA 1971

\title{
VLOGA PRVEGA BEOGRAJSKEGA PEVSKEGA DRUŠTVA V RAZVOJU SRBSKE GLASBE
}

\author{
Dimitrije Stefanović (Beograd)
}

V času, ko so turški vojaki stražili vrata beograjske trdnjave, ko je minilo že 153 let od ustanovitve Academiae Philharmonicorum v Ljubljani in ko v Zagrebu Vatroslav Lisinski dokončuje svojo drugo opero, se je sestalo v neki beograjski hiši turškega tipa v stanovanju Milana Milovuka devet ljubiteljev glasbe: pet Srbov na čelu z Milovukom in štirje tujci, med katerimi je bil Josif šlezinger. ${ }^{1} \mathrm{Ti}$ so 14. januarja 1853 ustanovili Beograjsko pevsko društvo. V pričujočem članku bomo poskušali na kratko podčrtati vlogo, ki jo je to društvo - prvo te vrste $\mathrm{v}$ Beogradu - v času svojega stosedemnajstletnega rodovitnega delovanja imelo pri širjenju srbske glasbene kulture. Pri tem bomo omenili tudi pomembno vlogo, ki jo je Beograjsko pevsko društvo imelo pri prebujanju domovinske zavesti Srbov in v razširjanju bratstva med južnimi Slovani.

Nastanek društva je bil prvi znak strnjenega glasbenega življenja v še vazalni Srbiji ne glede na to, da je bila naloga društva »skupno uživanje glasbe in muzikalno izobraževanje». Povsem razumljivo je, da so društvo sestavljali $v$ njegovem prvem obdobju, tj. od ustanovitve in še po prihodu Kornelija Stankovića (leta 1863) in slikarja Steve Tododovića vse do leta 1880 , samo moški glasovi in da je predstavljal repertoar tako imenovani Liedertafel," zbori večinoma nemških avtorjev, ki so jih večkrat peli v tujih jezikih.

$\mathrm{Z}$ novimi pravili leta 1864 , v katerih se poudarja »širjenje, podpiranje in izpopolnjevanje glasbe $\mathrm{v}$ domovini in zbujanje ljubezni $\mathrm{k}$ tej umetnosti, pri čemer je zlasti upoštevati značaj slovanske in srbske glasbe«, pa prodre v ospredje vse bolj, toda ne brez nasprotovanja, nacionalna smer. Zdaj se pojejo srbske ljudske pesmi in kompozicije slovanskih avtorjev. „Širjenje, podpiranje in izpopolnjevanje glasbe

${ }^{1}$ S. Djurić-Klajn, „Josif šlezinger, začetnik srpskog muzičkog života u XIX. veku«, "Jevrejski almanah", Beograd 1961-1962, 68-73.

${ }_{2}^{2}$ Liedertafel je posebna oblika manjšega moškega zbora, kjer so pevci med petjem sedeli okrog mize. Prim. Muzička enciklopedija II, 1963, 105 do 106. 
v domovini« predstavlja po ustanovitvi drugi pomemben korak v kulturnem in glasbenem življenju Beograda.

Številni koncerti in prireditve $\mathrm{v}$ dobrodelne namene $\mathrm{z}$ namenom podpirati druga društva, ustanove in posameznike pa so naslednji korak v mnogostranski dejavnosti Beograjskega pevskega društva, ki je tako imelo določen vpliv na kulturno in glasbeno življenje ne le Beograda, ampak tudi Srbije. Naj omenimo samo nekaj prireditev: Koncert v korist Bolnice siromašnih učencev (1865), v korist ustanovitve Srbskega narodnega gledališča (1869), v korist slabotnih hercegovskih otrok (1875), v korist Društva za pomoč ranjenim upornikom Bosne in Hercegovine (1876), za Srbe, prizadete v vojni (1877) in koncert $\mathrm{v}$ korist družine umrlega pesnika Djure Jakšića (1879).

Prav je, če pogledamo še odnos med Beograjskim pevskim društvom in Narodnim gledališčem, ker v tem društvu poganjajo tudi prve kali za poznejše delo v Narodnem gledališču «. ${ }^{3}$ Društvo je rado sprejemalo povabila, naj pomaga s svojimi koncerti posameznim kulturnim ustanovam. "Z nenavadnim navdušenjem in prizadevnostjo je večkrat prirejalo zabave $\mathrm{v}$ korist gradnje in vzdrževanja gledališča. Vendar pa se gledališka uprava ni vedno odzvala prošnjam Beograjskega pevskega društva in mu ni dovolila prirejati koncerte $\mathrm{v}$ lastno korist v gledališču, ko tu niso igrali, čeprav je vedela, da so koncerti najmočnejši vir za kritje stroškov društva, ki so $\mathrm{v}$ zvezi $\mathrm{z}$ njegovim obstankom, in da društvo, kot je to, ne more brez škode svojemu ugledu, kjerkoli prirejati koncertov. ${ }^{4}$

Pogosta gostovanja $\mathrm{v}$ skoro vseh večjih mestih na ozemlju današnje Jugoslavije, med katerimi so bili nekatera pod turško oziroma avstroogrsko oblastjo (Sremska Mitrovica, Smederevo, Negotin, Skopje, Vranje, Dubrovnik, Kotor, Cetinje, Mostar, Sarajevo, Split, Rijeka, Zagreb in še $\mathrm{v}$ mnogih drugih mestih), so nedvomno prispevala $\mathrm{k}$ ustanavljanju novih zborov. Tako je bilo npr. leta 1903 osnovanih v Beogradu enajst, v notranjosti Srbije pa okrog dvajset pevskih zborov.

Na turnejah zunaj naše dežele (1894 - Solun, Budimpešta, 1895 - Sofija, Plovdiv, Carigrad, 1896 - Kijev, Moskva, Petrograd, Njižnij Novgorod, 1899 - Berlin, Dresden, Leipzig, 1911 - Trst, 1914 Atene) so bili tujini prvič predstavljeni jugoslovanski skladatelji.

Vse večja dejavnost Beograjskega pevskega društva je dala mnogim avtorjem pobude za komponiranje zborovskih skladb vse od nacionalno rodoljubnih, prigodnih, liričnih, obdelav narodnih pesmi (Kornelije Stanković), prek »Kola» (Josip Marinković) do "Rukovetov« (Stevan Mokranjc) na eni strani, na drugi pa je dala pobude za ustvarjanje kompozicij na liturgične tekste. Tako se je oblikoval re-

3 Djurić-Klajn, »Muzički život u Beogradu pre 1869. godine«, jedan vek Narodnog pozorišta u Beogradu, Beograd 1968, 596-601, 599.

4 Kalik S., Spomenica Beogradskog pevačkog društva prilikom proslave pedesetogodišnjice, Beograd 1903, 29. 
pertoar, v katerem se odraža razvoj srbske zborovske literature. $\mathrm{Ob}$ proslavi petdesetletnice Beograjskega pevskega društva 25. maja 1903 je bil koncert, ki ga je sestavil Stevan Mokranjac. Program je obsegal prerez skozi srbsko pesem. Naslednji dan je bil »slavnostni koncert s tekmo srbskih pevskih društev « ${ }^{5}$ Kot je Beograjsko pevsko društvo prispevalo $\mathrm{k}$ ustanovitvi Zveze srbskih pevskih društev (leta 1903), tako je tudi kasneje aktivno sodelovalo pri osnovanju Južnoslovanske pevske zveze (leta 1924) in dve leti zatem priredilo prvo jugoslovansko glasbeno razstavo in svečan koncert, tokrat koncert sodobne jugoslovanske glasbe (leta 1926).

Eden najpomembnejših prispevkov srbski glasbeni kulturi pa je ustanovitev Srbske glasbene šole pod okriljem društva leta 1899, prve stalne šole $\mathrm{v}$ Beogradu in najstarejše glasbene šole na ozemlju ožje Srbije. To je današnja srednja glasbena šola »Mokranjac«, ki je že praznovala sedemdeseto obletnico ustanovitve. Ne pozabimo tudi na imena njenih ustanoviteljev: Stevan Mokranjac, Stanislav Binički in Cvetko Manojlović. K temu je treba še dodati, da sta že leta 1863 Kornelije Stanković in Milan Milovuk izdelala program za ustanovitev glasbene šole $\mathrm{v}$ Beogradu.

Ko naštevamo številne oblike dejavnosti Beograjskega pevskega društva, se zaustavimo tudi pri širjenju bratstva med jugoslovanskimi narodi. Že leta 1864 predvidevajo pravila, da lahko postane član društva "ne glede na spol, vero in narodnost vsak, ki je poznan kot pošten človek ... ${ }^{6}$ Leta 1869 je bil hrvaški škof Jurij Strossmayer v Beogradu gost beograjskega metropolita Mihajla. Ker je Beograjsko pevsko društvo cenilo Strossmayerjeve zasluge za narod, mu je priredil baklado pred zgradbo metropolije. Tedanji predsednik društva Jovan Bošković se je obrnil k zbrani množici, ki je gledala na istem oknu srbskega metropolita Mihajla in hrvaškega škofa Strossmayerja, in rekel: "Vidite, da ni treba, da cerkve razdvajajo sinove enega naroda«. ${ }^{7}$

Poudariti je treba tudi primer prvega dirigenta, ki ni bil Srb, ampak Slovenec Davorin Jenko (1834-1914). ${ }^{8}$ Jenko je prvi glasbenik, ki je bil izvoljen za člana Srbskega znanstvenega društva (1869), za častnega člana Srbske matice $\mathrm{v}$ Novem Sadu in pozneje za rednega člana Srbske kraljeve akademije (1888). Uspešno je deloval kot dirigent Pančevskega srbskega cerkvenega pevskega društva od leta 1863 do 1865 . Potem je odšel v Beograd, kjer je bil od 1865 do 1877 zborovodja Beograjskega pevskega društva. Leta 1871 je postal ka-

5 Program tega koncerta in seznam triindvajset društev sta objavljena v delu K. P. Manojlovića, Spomenica Stevanu St. Mokranjcu, Beograd 1923, 98-100.

6 Kalik S., op. cit., 32.

7 Lazarević S. V., "Beogradsko pevačko društvo (1853-1953)«, Godišnjak Muzeja grada Beograda, knj. II, Beograd, 1955, 353-376, posebno str. 359 , opomba 33.

8 Za Davorina Jenka prim. Cvetko D., Davorin Jenko i njegovo doba, Srpska akademija nauka, Muzikološki institut, knj. 4, Beograd 1952. 
pelnik beograjskega Narodnega gledališča, kjer je delal polnih trideset let. Medtem ko je v Pančevu postavil temelje sistematskemu pevskemu delu, je Beograd prinesel nov umetniški kriterij in duh proti diletantizmu. Jenkovo delo v Narodnem gledališču je bilo mnogostransko: komponiral je uverture in glasbo za več kot osemdeset gledaliških del, dirigiral je vse predstave, kjer je bila glasba, in poučeval je dramske igralce v petju. Posamezne igre so se obdržale na repertoarju predvsem zaradi Jenkove glasbe. Jenko je tudi avtor dveh himen, slovenske "Naprej, zastave slave» in stare srbske »Bože pravde«. Mnoge zborske kompozicije (»Bože bratimstva«, "Strunam", "Dunte vetri«) in samospeve »je prenesel v srca premnogih pevcev svojega rodu. Jenko je imel stike s Srbi še na Dunaju, v tedanjem središču panslavističnih idej, kjer se je po Ljubljani in Trstu glasbeno izobraževal. Kornelije Stanković ga označuje »kot svojega prizadevnega tovariša in dobrega strokovnjaka $\mathrm{v}$ glasbenih stvareh tistega časa«. Hrvaški etnomuzikolog Franjo Kuhač, ki je obiskal Jenka v Pančevu, pravi, da je $\mathrm{v}$ njem našel »izobraženega človeka, polnega ljubezni in spoštovanja do srbske glasbe«. Stevan Mokranjac, največji Jenkov sodobnik, govori $\mathrm{z}$ velikimi simpatijami o svojem kolegu: „V tistem času nismo imeli boljšega predstavnika glasbene umetnosti, kot je bil Jenko, in zato smo ga imeli radi, ga ljubimo in ga še bomo ljubili kot najboljšega od vseh slovanskih glasbenikov, ki so pri nas delali. «9 Priznanje Jenku izraža v svojem inspiriranem članku Miloje Milojević, ko pravi: »Treba je reči, da naša jugoslovanska glasbena kultura pri Srbih mnogo dolguje Davorinu Jenku«. ${ }^{10}$ »Jenko je zelo mnogo prispeval srbski glasbi, ker je na zdravih in trdnih temeljih zgradil lepo stavbo srbske glasbene kulture in to z veliko ljubeznijo ter poln umetniškega zanosa skozi vse svoje življenje«. ${ }^{11} \mathrm{Ne}$ pozabimo, da je Jenko umrl v Ljubljani leta 1914 kot srbski državljan.

Iskreno rodoljubje se je odražalo $\mathrm{v}$ težnji, da se ohrani nacionalna smer, ki je bila postavljena že vse od Kornelija Stankovića naprej; dosledno jo je uresničil Stevan Mokranjac, nato pa sprejel tudi Kosta Manojlović. Ta je razširil nacionalno orientacijo na jugoslovanstvo in celo na panslovanstvo. Naj še dodamo, da se nam danes zdi kot da je Kosta Manojlović gledal glasbo v širokih ekumenskih okvirih, ko je izvajal dela zahodne glasbene literature (na primer Palestrinovo »Missa Papae Marcelli« leta 1925 in slovenske božične pesmi v Saborni cerkvi v Beogradu!). Potrdilo za to dajo tudi programi dveh jugoslovanskih koncertov, od katerih je bil prvi sestav-

${ }^{9}$ Djurić-Klajn S., Razvoj muzičke umetnosti u Srbiji, v knjigi Historijski razvoj muzičke kulture u Jugoslaviji, Zagreb 1962, 595-604, 621; Djurić-Klajn S., »Beogradsko pevačko društvo«, Muzička enciklopedija I, 1958, 141-142. 291.

10 Milojević M., »Intimni lik Davorina Jenka«, Zvuk 8-9, Beograd 1935,

$11 \mathrm{M}$. Tomandl, Spomenica Pančevačkog srpskog crkvenog društva 1838 do 1938, Pančevo 1938, 128. 
ljen iz del srbskih, hrvaških in modernih slovenskih avtorjev ter enega bolgarskega skladatelja. Jugoslovanstvo Prvega beograjskega društva ${ }^{12}$ se kaže tudi $\mathrm{v}$ izvolitvi dveh Hrvatov za predsednika: univerzitetnega profesorja, akademika dr. Viktorja Novaka, bivšega predsednika Hrvatskega pevskega združenja "Lisinski« iz Zagreba, in dr. Ivana Ribarja, bivšega predsednika Narodne skupščine (leta 1926). $\mathrm{Za}$ častna člana društva pa sta bila svoj čas izvoljena Čeha Dragotin Čižek in Vaclav Horejšek.

Pomembne korake v glasbenem vzponu društva predstavlja izvajanje na vse višji umetniški ravni vokalnih del naših tedanjih modernih skladateljev (Konjovića, Hristića, Milojevića), vokalno instrumentalnih del slovanskih in drugih evropskih avtorjev (Dvořákovega oratorija "Stabat Mater" in kantate »Mrtvaški ženin", Perosijevega "Kristusovega trpljenja«, Verdijevega "Requiema«) in končno Händlovega »Mesija« v dvorani Kolarčeve ljudske univerze leta 1937.

Prvo beograjsko pevsko društvo je vodilo skozi 117 let okrog petdeset zborovodij. Med njimi se odlikujejo naši najbolj znani dirigenti, skladatelji, glasbeni pedagogi in navdušeni organizatorji glasbenega življenja v Srbiji: Kornelije Stanković, Davorin Jenko, Josif Marinković, Stevan Mokranjac, Stanislav Binički, Miloje Milojević, Stevan Hristić, Kosta Manojlović, Josip Štolcer-Slavenski, Vojislav Ilić, Predrag Milošević, Svetolik Paščan-Kojanov in drugi. S svojim plodnim delom in pomembno vlogo se je Beograjsko pevsko društvo vključilo v temelje srbske glasbene kulture.

\section{SUMMARY}

It was in 1853, when Turks still kept guards at the Belgrade fortress, that the first Belgrade Choral Society was founded. During their first period the Society's repertoire consisted of Liedertafel pieces composed mainly by German authors. In 1864 new statutes made provision for works by Slavonic and Serbian composers. The idea for the foundation of the Belgrade National Theatre (1868) also grew up within the Society. The choir toured a number of cities which are now on the territory of Yugoslavia, but were then under Turkish or Austro-Hungarian rule and after 1894 tours were organized to different foreign countries. An important contribution to the development of musical culture in Serbia was made in 1899, when the first Serbian Music School in Belgrade was founded under the Society's auspices. - It is interesting to note the Yugoslav character of the Society's policy, especially the activity of the first conductor who was not a Serb, but the Slovenian musician Davorin Jenko. Two Croats were also elected as the Society's presidents. During the hunderd and seventeen years of its existence, the Society's choir has been directed by almost 50 conductors, among them the most prominent conductors, composers, teachers and organizers of musical life in Serbia. By their manifold activities the First Belgrade Choral Society was able to lay solid foundations for the development of musical culture in Serbia. letu 1920

${ }^{12}$ Preimenovanje v Prvo beograjsko pevsko društvo se je izvršilo po 